\title{
European analytical column number 45
}

\author{
Wolfgang Buchberger ${ }^{1}$ - Slavica Razic ${ }^{2}$
}

Published online: 27 April 2017

(C) Springer-Verlag Berlin Heidelberg 2017

\section{EuCheMS 8 European Chemical Sciences Division of Analytical Chemistry}

\section{Information from the EuCheMS Division of Analytical Chemistry}

The impact of analytical chemistry on progress in science is significant. Vice versa, progress in analytical chemistry is essential to provide the necessary input to other research fields. The Division of Analytical Chemistry (DAC) can be seen as a common platform for activities initiated by the member societies of EuCheMS. Concerted actions will be much more efficient than a variety of isolated activities.

DAC has started the year 2017 with Slavica Razic (University of Belgrade) as the new Chair. She will be supported by the members of the Steering Committee consisting of Jiri Barek (Czech Republic) as Treasurer, Wolfgang Buchberger (Austria) as Secretary, Sibel Özkan (Turkey), Christian Rolando (France), Charlotta Turner (Sweden), and Paul Worsfold (United Kingdom) as Immediate Past Chair. At

Wolfgang Buchberger

wolfgang.buchberger@jku.at

Slavica Razic

slavica.razic@pharmacy.bg.ac.rs

1 Analytical Chemistry, University Linz, Altenbergerstrasse 69, 4040 Linz, Austria

2 Department of Analytical Chemistry, Faculty of Pharmacy, University of Belgrade, Vojvode Stepe 450, Belgrade 11222, Serbia the Annual Meeting 2016 of DAC in Seville, the Delegates expressed their sincere thanks to Paul Worsfold for his highly efficient and most successful work as Chair of DAC from 2011 to 2016.

This year, the main DAC event will be Euroanalysis XIX to be held in Stockholm from 28 August to 1 September 2017 (http://euroanalysis2017.se). Along the lines of the long established tradition of Euroanalysis that started in Heidelberg in 1972, the meeting will cover all aspects where analytical chemistry plays a role, including fundamental and applied sciences. It has become a premier European meeting for the exchange of new ideas in analytical sciences. The Organizing Committee, chaired by Charlotta Turner and Jonas Bergquist, invites the analytical community to participate and to present their most recent and innovative research work.

Various activities are initiated and carried out within the study groups of DAC. In this European Analytical Column, the current activities are summarized, which should stimulate input from analytical chemists potentially interested in cooperation with these study groups.

\section{Study groups of DAC}

The objectives of the study group "Analytical Chemistry in Archaeology" (Head: Prof. Miltiades Karayannis, Greece) are to demonstrate the importance of analytical chemistry for the collection of scientific information valuable to archaeologists and art historians in order to investigate, date, and authenticate archaeological objects and works of fine art. The study group seeks to explore and propose methods for these purposes, and to recommend to archaeologists the proper analytical techniques for sampling, analysis, and evaluation of the data. Collaboration and the exchange of ideas of analytical 
chemists between relevant European scientific laboratories will be strengthened and new trends in the scientific activities and publications in this area identified.

The study group "Bioanalytics” (Head: Prof. György Horvai, Hungary) aims to bring the analytical and the bioanalytical chemistry communities closer together. This is still a formidable task because a structured community of bioanalytical chemists does not appear to have formed yet. An indication of change is the fact that analytical journals publish more and more bioanalytical papers, including contributions from European authors. The programme of the 2016 EuCheMS Chemistry Congress in Seville included a session dedicated to bioanalytics. The main (invited) lecture in that session was presented by Prof. Jonas Bergquist from Sweden. In another session, the invited lecture given by Prof. Romà Tauler discussed chemometrics techniques applied to high throughput omics. Members of the study group have closely followed bioanalytical events and the development of bioanalytical curricula at Universities in several European countries. The Euroanalysis conference 2017 will present an opportunity for establishing contact with colleagues involved in bioanalytics, but not yet active in DAC.

The aims of the study group "Chemometrics" (Head: Prof. Romà Tauler, Spain) include the promotion of chemometrics in Europe, the organization of chemometrics sessions at the Euroanalysis conference and at other EuCheMS-related conferences, and the realization of European schools and workshops on chemometrics. For the year 2017 two main activities are envisaged. First, the members of the study group are preparing a tutorial on chemometrics for the journal Analytical and Bioanalytical Chemistry. The other activity is the preparation of the chemometrics session at the Euroanalysis conference in Stockholm where, in addition, a chemometrics course will be offered.

The study group "Education” (Head: Prof. Reiner Salzer, Germany) investigates successful new approaches in teaching analytical chemistry. Some approaches are based on didactic advances, some on reformed contents, and others introduce advanced digital tools. Members of the study group also participate actively in establishing quality standards for the curricula in chemistry coursework. Outstanding new approaches will be discussed at the Symposium Education during the Euroanalysis conference in Stockholm (scheduled for Tuesday, 29th August 2017). Everybody is invited to participate in the discussion or to get inspirations for her/his own teaching duties.

The aim of the study group "History" (Head: Prof. D.T. Burns, UK) is to study and publish accounts of the history of analytical chemistry in Europe with reference to indi- vidual countries, specific locations, professional bodies and personalities. Six recent publications can be found in the Annual Report 2016 on the DAC website (http://www. euchems.eu/divisions/analytical-chemistry). Meanwhile, the material on the history of the adulteration of coffee has been published (D.T. Burns, L. Tweed, M.J. Walker, "Ground roast coffee: Review of analytical strategies to estimate the geographic origin, species authenticity and adulteration by dilution", Food Anal.Methods (2017), doi: 10.1007/s12161-016-0756-3). Other interesting publications to be mentioned include an article about Paul Coremans (1908-1965), a pioneering chemist in the application of scientific techniques to the visual arts (in press), and an account of the contributions of G.W. Monier-Williams to the improvement in quality and purity of foodstuffs (in preparation). Monier-Williams is best known for his method for the determination of sulfite in foods first published in 1927 , but still in current use as a reference method.

The study group "Quality Assurance” (Head: Prof. Elin Gjengedal, Norway) follows the development of quality assurance and metrology in analytical chemistry and produces guidelines for assessing the quality of results, which ultimately can create a new basis for decision-making that may have an impact on the way research is carried out. The existing link to Eurachem (https://www.eurachem.org) is particularly important, connecting the study group with a network of organizations in Europe having the objective of establishing a system for the international traceability of chemical measurements and the promotion of good quality practices. Among other things, Eurachem is publishing guides that are reviewed 5 years after publication to assess the need for revision. Recently, the Eurachem Education and Training Working Group issued a new Third Edition of the wellknown Eurachem/CITAC "Guide to Quality in Analytical Chemistry-An Aid to Accreditation". In 2014 the Second Edition of "The Fitness for Purpose of Analytical Methods: A Laboratory Guide to Method Validation and Related Topics" was published. This guide was first issued in 1998, and has, over the years, been one of the most popular of the Eurachem guides. The working language of Eurachem is English; however, thanks to the hard work of members of Eurachem, the guides and leaflets are available in a number of other languages. Activities planned for the DAC study group "Quality Assurance" in 2017 include the continued input to Eurachem, the publication of results of quality assurance in appropriate journals, the contribution to analytical conferences, e.g., ANAKON 2017, Euroanalysis 2017, and the finalization of the revision of two standards used globally for accreditation: ISO/IEC 17025 for testing laboratories and ISO 17034 for reference material producers. 